\title{
Morphological characteristics of honey bees of the Volga region
}

\author{
Natalia Evgenevna Zemskova ${ }^{1 *}$, Vener Nurullovich Sattarov $^{2}$, Anatoly Ivanovich Skvortsov ${ }^{3}$, and Vladimir Grigorievich \\ Semenov $^{3}$ \\ ${ }^{1}$ Samara State Agrarian University, 446442 Kinel, Samara region, Russia \\ ${ }^{2}$ Bashkir State Pedagogical University M. Akmulla, 450008 Ufa, Russia \\ ${ }^{3}$ Chuvash State Agricultural Academy, 428003 Cheboksary, Russia
}

\begin{abstract}
Declining bee populations and decreasing marketability of apiaries pose the necessity for a comprehensive monitoring of the morphological characteristics of honeybees. The monitoring was performed in an introgressive aspect for the first time in the Volga region (Samara region) to preserve the local population of the Middle Russian race (Apis mellifera mellifera L.). Moreover, the race of queen bees was identified through the assessment of drones. Based on the race identification, small population structures of the native forest bee were revealed, which is a prerequisite for restoration of its genetic resources with the corresponding restriction of the import of bees from the southern regions where other taxonomic groups are bred.
\end{abstract}

\section{Introduction}

The Volga region is a historical habitat of the Middle Russian or dark-colored European forest bee (Apis mellifera mellifera L.).

At present, widespread honeybee colony losses can be observed in the region, which lead to a decrease in the production of marketable honey $[1$, p. $88 ; 2$, p. $53 ; 3$, p. 183].

These negative changes are due to the anthropogenic impact on the ecosystem, which is manifested in both the technogenic contamination of the biosphere components and a direct change in the genotype of bees through a large-scale unsystematic hybridization with "southern" races that results in crossbreeding of the Middle Russian race followed by decreased adaptive abilities of hybrids.

Therefore, bees preservation, in the evolution of which natural selection played a crucial role, is important for maintaining the required level of ecosystem biodiversity [4, p. $20 ; 5$, p. $5 ; 6$, p. $24 ; 7$, p. $12 ; 8$, p. $19 ; 9$, p. 183].

In general, it can be noted that irreplaceability of the hereditary basis of natural races formed during a long evolution initiated work on the restoration of native bees.

The first stage of this process was race identification of bee colonies by assessing morphotypes and morphometric characteristics of bees.

\section{Material and methods}

The object of study was the honeybee population in Samara region. The study was carried out in 2015-2018 at Samara Agrarian University. The study material was a sample of individual workers and drones of honeybees (Apis mellifera) from apiaries in 27 administrative districts of Samara region.

The study employed a comprehensive morphological approach for taxonomic assessment of Apis mellifera: a method for analyzing morphotypes of honeybee workers and drones by cuticle color and a morphometric method for assessment of honeybee workers and drones. In each region, 1,350 workers and drones were investigated.

Race identification of honeybee workers by cuticle color was performed according to the method of F. Ruttner (2006), which identifies bees of the Middle Russian race as classes O and e [10, p. 126-132] (Fig. 1).

The following classes of the abdomen coloring (morphotypes) can be distinguished in honeybee workers: O - completely dark cuticle, without brown or yellow corners; e - small brown or yellow corners on the cuticle, up to $1 \mathrm{~mm}^{2}$; E - large brown or yellow corners on the cuticle, from $1 \mathrm{~mm}^{2} ; 1 \mathrm{R}$ - one brown or yellow ring on the cuticle; $2 \mathrm{R}$ - two brown or yellow rings on the cuticle; $3 \mathrm{R}$ - three main brown or yellow rings on the cuticle. Race identification of drones by cuticle color was also performed according to the method of F. Ruttner, according to which drones of the Middle Russian race are identified as classes $\mathrm{O}$ and $\mathrm{i}_{\mathrm{s}}$ (Fig. 2).

\footnotetext{
* Corresponding author: zemskowa.nat@yandex.ru
} 

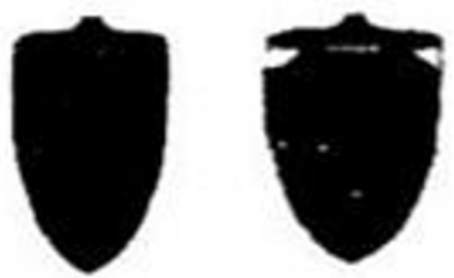

e

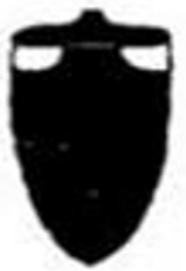

$\mathbf{E}$

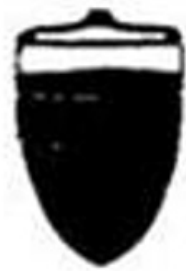

$1 \mathbf{R}$
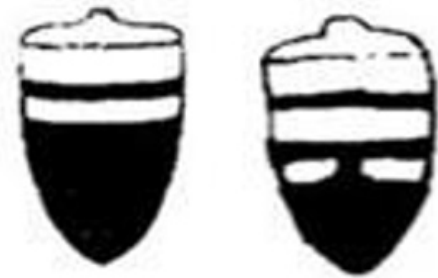

$2 \mathbf{R}$

$3 \mathbf{R}$

Fig. 1. Coloring classes of honeybee workers (morphotypes)

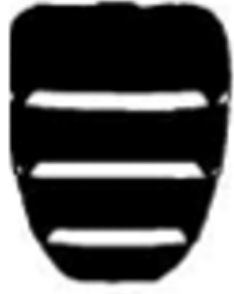

$\mathbf{O}$

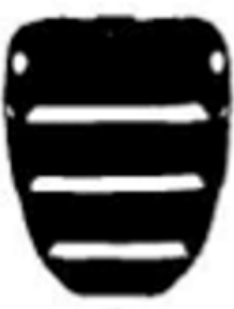

$\mathbf{i}_{\mathbf{i}}$

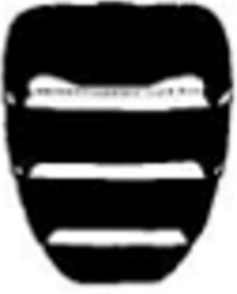

is $_{\text {s }}$

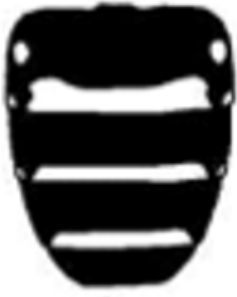

is

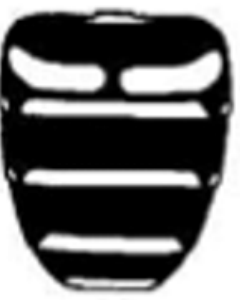

I

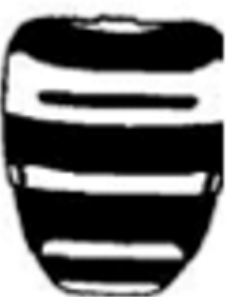

$1 \mathrm{R}$

Fig. 2. Drone morphotype classes

According to this classification, the following morphotypes can be distinguished in drones: $\mathrm{O}-$ dark; $\mathrm{i}_{\mathrm{i}}$ - small "islands" (in different positions); $i_{\mathrm{s}}-$ a wide saddle-shaped strip; $i_{\text {is }}$ - small "islands" and a wide saddle-shaped strip; I - large "islands"; 1R - one ring [10, p. 150-151].

Morphometric assessment performed according to the classical method identified 10 exterior characteristics in honeybee workers: proboscis length; length and width of tergite 3 ; length and width of sternite 3 ; length and width of the right front wing; cubital index (Ci); tarsal index and discoidal displacement [10, p. 131-161]. The color of hairs on the abdomen of drones was determined using the Goetze color scale [10 p. 152].

\section{Results and discussion}

Honeybee workers of a dark European race exhibit from dark gray to black tergite coloring (morphotype $\mathrm{O}(\mathrm{h})$ ), and in some cases the second ring has brown edges or "corners" (morphotype e). Drones either have dark segments on the abdomen (morphotype O) or a wide saddle-shaped strip (morphotype $i_{\mathrm{s}}$ ).

When assessing this characteristic, the prevalence of yellow and brown inclusions should be taken into account, which are characteristic of many "southern" bee races and were not previously observed in the Middle Russian bees in their natural habitat.
Thus, the assessment of color variations in Apis is an indicator of alien bees, which enables identification of the dynamics of changes in native populations.

Six morphotype classes were recorded in honeybee workers in the field and laboratory studies (Fig. 3).

The data presented show high heterogeneity of body color in Middle Russian bees inhabiting Samara region, which is an indicator of transformation of their aboriginal structure. In the studied apiaries, bees that do not correspond to the taxonomic characteristics of the Middle Russian race are prevailing.

Over the past three years, the average number of Apis mellifera mellifera L. was quite low and amounted to $36.8 \%$ of the total number of studied bees. At the same time, a comparative analysis of the dynamics of bee morphotypes revealed an increase in the range of colors of the bee cuticle each subsequent year relative to the previous one.

In many regions, the occurrence or increase in the number of morphotypes characteristic of "southern" races was recorded together with a quantitative reduction in color that is characteristic of the Middle Russian race.

This noticeable variety in the color manifestation can be considered as confirmation that hybridization or crossbreeding occur in the habitat of bees of the Middle Russian honeybee race, which are characterized by the morphotypes: E, O (s), 1R, and 2R. 


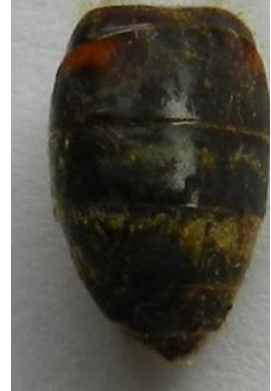

e

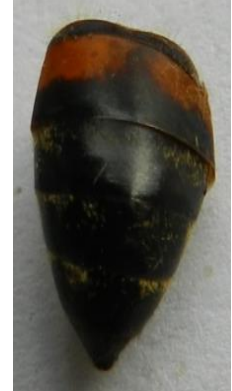

$\mathbf{E}$

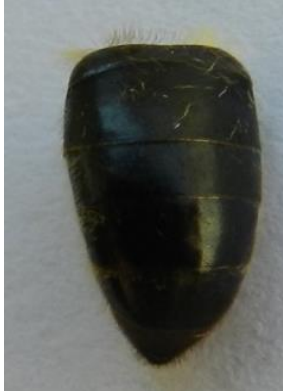

$\mathbf{O}(\mathbf{4})$

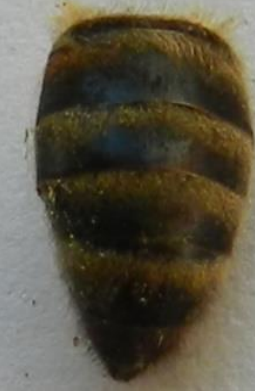

$\mathbf{O}(\mathbf{c})$

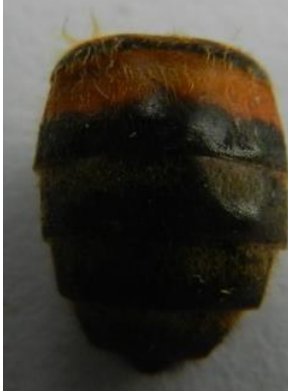

1R

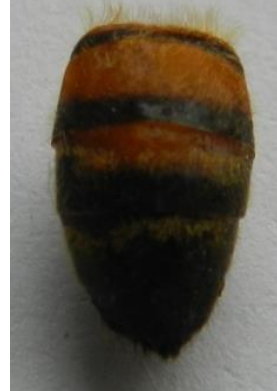

2R

Fig. 3. Morphotypes of Apis mellifera recorded from Samara region

Analysis of the morphotypes observed in the soillandscape zones of Samara region allows us to distinguish the northeastern forest-steppe subpopulation of bees of the Middle Russian race and individual preserved islands, which may have been previously allocated to the western forest-steppe, buffer and steppe subpopulations.
The results of studies of the ratio of drones with different intensity of tergite coloring (morphotypes) in the apiaries of administrative regions of four soil-landscape zones in Samara region are presented in Fig. 4.
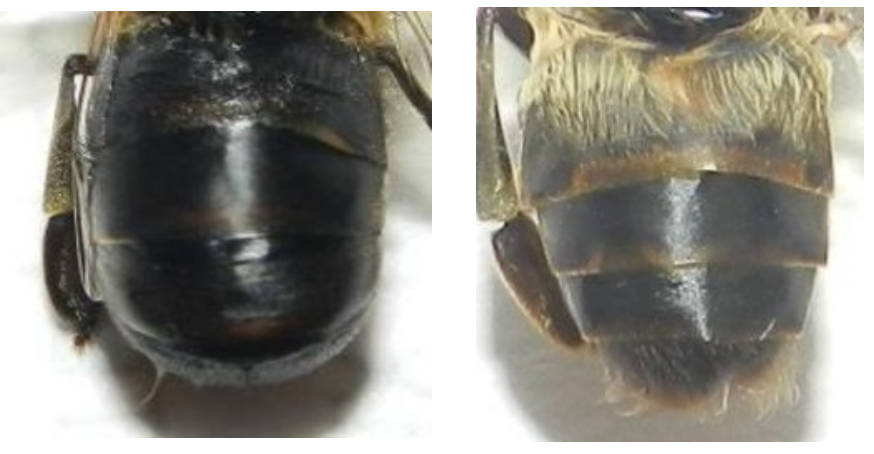

$\mathbf{O}$ $\mathbf{i}_{\mathrm{s}}$
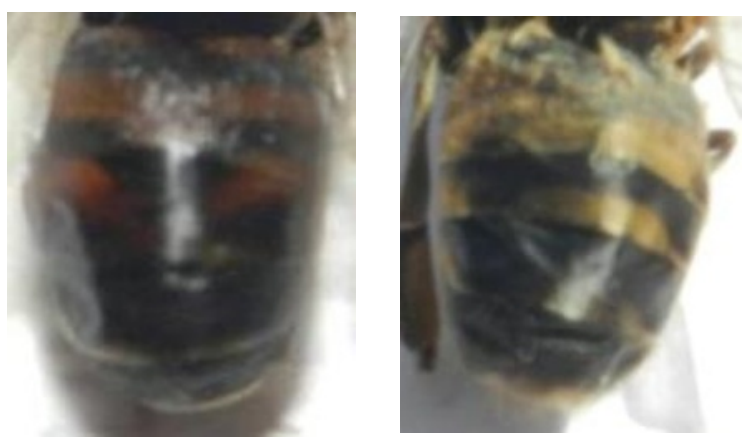

I

1R

Fig. 4. Morphotypes of drones recorded from Samara region

The study of the morphotype structure of drones recorded from Samara region showed high heterogeneity of tergite coloring and four variants of morphotype classes: $\mathrm{O}, \mathrm{i}_{\mathrm{s}}, \mathrm{I}$, and $1 \mathrm{R}$. In the studied apiaries, drones prevailed and corresponded to the morphotypes of Middle Russian bees ( $\mathrm{O}$ and $\mathrm{i}_{\mathrm{s}}$ ). Over the past three years, the average number of Apis mellifera mellifera L. individuals amounted to $60.6 \%$ of the total number of studied bees.

However, the dynamics of this indicator for soillandscape zones shows a steady, consistent decrease in the number of individuals of morphotype classes characteristic of the Middle Russian race.

Thus, an observed decrease in the adaptive mechanisms and resistance of bees is due to changes in the evolutionarily developed structures of Apis mellifera, which can lead to the loss of valuable economically useful traits characteristic of the Middle Russian race.

When identifying morphotypes, a classical morphometric analysis of honeybees was carried out. At the same time, studies of honeybee workers revealed a clear correspondence to the Middle Russian bee race only in apiaries of several settlements.

Thus, the forest-steppe zone includes 14 regions, the buffer (transitional) zone -6 , the steppe zone -6 , and the dry-steppe region - 1 .

The studies of the exterior features of bee workers revealed a clear correspondence to the breed standard of the Central Russian bee breed in only five settlements of five regions of the forest-steppe zone; in two - of the buffer zone; in one - of the steppe zone. The remaining settlements of the Samara region had a high percentage of halfbreed individuals.

When assessing the breed affiliation of bee colonies, an important role should be given to the study of the morphology of drones. Apis drones, having a haploid character of inheritance, can more accurately characterize the pedigree purity of families, because purebred queens produce drones of the same type. As a result of this, the next step was to determine the thoroughbredness of the queens in the bee colonies by identifying the breed of drones. 
The obtained morphometric measurements of the drones of the forest-steppe zone make it possible to identify seven settlements in six regions, where the drones were most consistent with the Apis mellifera mellifera L. standard. There were two such settlements in the buffer zone located in only one region. In the steppe zone there was one, and in the dry steppe zone - also one.

Thus, the analysis of the parameters of drones, to no lesser extent than the analysis of working bees, allows us to conclude that the process of halfbreeding of bees or adverse anthropogenic influences on the subpopulation structure of bees is widespread. As a result, there is a high percentage of crossbred queens, which is caused, in our opinion, by the following reasons: the interest of many beekeepers in the use of early queens and "southern" bee packages for the intensive development of beekeeping; the lack of recognition of the priority of the Central Russian bee breed at the legislative level, and, consequently, the lack of breeding centers for its breeding in the Samara region.

Of the total number of colonies analyzed, only 50 $(4.0 \%)$ of bee workers $(1,215$ ind.) were identified as the Middle Russian race, that is, the remaining 1,165 colonies (96.0\%) were hybrids.

The largest number of Middle Russian bee colonies was found in the forest-steppe zone - $30(4.5 \%)$, in the transitional zone $-15(5.8 \%)$, and in the steppe zone -5 $(1.9 \%)$. In the dry-steppe zone all bees were hybrids. Of the total number of bee colonies analyzed by drones (1,215 ind.), Middle Russian bees accounted for 65 $(5.3 \%)$, and the remaining $1,150(94.7 \%)$ individuals were hybrids.

The largest number of Middle Russian bees accounted for the forest-steppe zone was $40(6.0 \%)$, in the transition and steppe zones their number was almost the same: 10 $(3.8 \%)$ and $10(3.7 \%)$, respectively; in the dry-steppe zone, only 5 out of $40(12.5 \%)$ studied bee colonies were Middle Russian bees.

The unfavorable situation in beekeeping is further aggravated by the fact that the Samara region is a region with a high anthropogenic load, due to which the region is characterized by a significant disturbance of the main natural landscapes and the almost complete absence of territories not affected by economic activity and, as a consequence, a negative impact on the flora and fauna. In this regard, we monitored phenotypic anomalies of bees.

Visual studies of bees made it possible to identify two variants of morphological eye mutations in working bees: brown and garnet complex and simple eyes. Drones revealed one variant of morphomutations: brown complex and simple eyes. After analyzing the working bees and drones for the presence of anomalies, we can conclude that it is possible that the presence of bees with an abnormal eye color in all areas of the study area is the result of contamination of bees with ecotoxicants and the result of hybridization (halfbreeding) of once a local population of Apis mellifera mellifera L. The maximum number of bees with anomalous eye color falls on the areas where the largest number of half-breed bees was identified.

As is known, hybrid forms of bees, characterized by different classes of morphotypes, have heterogeneous physiological parameters, which gradually leads to changes in the adaptive mechanisms of aboriginal forms of bees and a decrease in resistance to diseases. As a result, disturbances in the processes of embryo- and ontogenesis of insects occur, which is reflected in changes in the evolutionarily developed structures of bee populations and, in general, regional ecosystems.

\section{Conclusion}

Our study shows that a vast majority of the investigated bee colonies in apiaries in Samara region (about 95.0\%) are hybrids; however, only $4.0-5.3 \%$ of them can be referred to the Middle Russian race. The number of Middle Russian bee colonies by drones was 15 (1.3\%) more, which indicates the presence of some biological potential for restoration of the native population of bees both in this region and in the neighboring regions (Chuvashia, Bashkortostan, etc.).

\section{References}

1. N.E. Zemskova, V.N. Sattarov, V.R. Tuktarov, Morphological characteristics of honeybees in the steppe zone of Samara region Morphology 143(3), 88 (2016)

2. R.T. Klochko, S.N. Lugansky, A.V. Blinov, Ten reasons for the death of bees in 2015 Apiculture $\mathbf{1}$, 53-54 (2016)

3. M.D. Meixner, R. Büchler, C. Costa et al., Honey bee genotypes and the environment $\mathrm{J}$. Apicultural Research 53(2), 183-187 (2014)

4. N.N. Grankin, N.N. Vereshchak, White-eyed drones in Oryol region Apiculture 8, 20-21 (2014)

5. A.G. Mannapov, L.I. Khoruzhiy, N.A. Simoganov, L.A. Redkova, Technology for the production of apiculture products according to the law of the natural standard (Prospect, Moscow, 2016)

6. I.A. Morev, L.Ya. Moreva, P.V. Radchenko, Analysis of bee races in Krasnodar region by the color of the abdomen Apiculture 5, 24-26 (2019)

7. S.A. Pashayan, K.A. Sidorova, Ecological problems of apiculture in Tyumen region Apiculture 1, 12-13 (2018)

8. A.I. Skvortsov, V.N. Sattarov, V.G. Semenov, Morphotypes and some morphological changes in Apis mellifera in the Chuvash Republic Apiculture 1, 19-21 (2018)

9. M. Heil Extrafl oral nectar at the plant-insect interface: A spotlight on chemical ecology, phenotypic plasticity, and food webs Annual Review of Entomology 60, 213-232 (2015)

10. F. Ruttner, Technique of breeding and selection of bees: practical guide: translated from German (AST: Astrel, Moscow, 2006) 